\title{
Solar Hot System and Design of Buildings
}

\author{
Yibing Xue, Jie Zhang \\ School of Architecture and Urban Planning, Shandong Jianzhu University,Jinnan,China \\ Email: 344836869@qq.com
}

Received 2013

\begin{abstract}
Domestic solar hot water system, the use of the status quo and existing problems, by analyzing the solar water heating equipment and building integrated and building integrated design.
\end{abstract}

Keywords: Solar Hot Water System; Benefit; Style; Solar Catch Heat Apparatus; Design of Buildings

\section{Current Situation and Problems}

China has abundant solar energy resources, and about twothirds of the country total solar irradiance approaching or exceeding 600 especially in the north, the vast areas of the Northwest, abundant sunshine, and laid a good condition in China's use of solar energy(Table 1).

With the constant attention of the national energysaving and environmental protection, the use of solar energy technology in the country to be developed by leaps and bounds. One of the major forms of solar energy as the use of solar hot water systems, by virtue of the many advantages of environmental, ecological, energysaving, economic rapid promotion, began to millions of households.

Solar hot water equipment is not a long time in domestic applications, the combination of solar equipment and residential is still at primary stage[1]. Currently, people tend to value only the functionality of the solar hot water equipment, to the neglect of other aspects of the problem. As messy mercy on the roof, different size specifications, the disorder of the pipeline, the metal component caused by light reflection, resulting in a strong visual pollution, affecting the building aesthetics and building facades effect, sometimes improperly installed and may even cause potential safety problems such as water heaters fall wounding roof broken, housing leaking.

\section{Building Integrated Solar Energy}

In order to solve the above problem, minimizing its negative effects on the building while making use of solar energy, and making it become an organic whole with the buildings, thus, we put forward the concept of " Solar energy and Building integrated", that is, from two aspects of solar energy application technology and beautiful architectural environment, considering the use of so- lar energy in the construction planning and design, and making it become an organic component of the whole building through reasonable design. In summary, it is to make full use of external parts of the solar energy that building can use, and to realize external harmony of in order to solve the above problem, minimizing its negative effects on the building while making use of solar energy, and making it become an organic whole with the buildings, thus, we put forward the concept of "Solar energy and Building integrated", that is, from two aspects of solar energy application technology and beautiful architectural environment, considering the use of solar energy in the construction planning and design, and making it become an organic component of the whole building through reasonable design. In summary, it is to make full use of external parts of the solar energy that building can use, and to realize external harmony of landscape building. Specifically speaking there are four meanings:

1) Making full use of the sunny part of the building (such as the sunny slope, roof and so on) to install solar equipment;

2) Joining with community planning, architectural design, equipment installation and acceptance, and saving the cost of solar equipment;

3) Combining solar energy systems and building organically, to make them harmony in appearance;

4) When design, solar component can be used as architectural component and bear some building functions.

At present, the state introduced technical regulations of using solar energy equipment in the construction project, the purpose of it is through the standardization of solar products to realize the standardization of the its installation and use, making the use function of solar equipment with building a good combination, thus forming a organic whole. 
Table 1. Solar thermal energy classification.

\begin{tabular}{lccccc}
\hline & \multicolumn{2}{c}{ solar thermal energy classification } & & \\
\hline \multicolumn{1}{c}{ rank } & one & two & three & four & five \\
\hline Annual sunshine hours(h/a) & $3200-3300$ & $3000-3200$ & $2200-3000$ & $1400-2200$ & $1000-1400$ \\
Total annual solar radiation(MJ/a) & $6680-8400$ & $5852-6680$ & $5016-5852$ & $4818-5016$ & $3344-4818$ \\
remark & most & more & medium & poor & worst \\
\hline
\end{tabular}

\section{Implementation of Solar Energy and Building Integrated Design}

\subsection{Combined with the Wall}

The buildings south facade good illumination condition, can take advantage of the window sill wall design of the solar collector and the wall of the south facade combination. The essence of the flat-plate collector as part of the facade wall, solar equipment at the same time meet their also meet certain structural and architectural features. The solar collector wall from outside to inside by translucent insulation coating, photothermal conversion layer , wall support and thermal conductivity layer, collector tube, foam insulation layer, interior wall supporting layer, interior wall smear layer section composition. When the sun along an angle of incident to the wall, the press effective projected cross-section to obtain the effective light energy through the transparent insulation coating, incident to the light-heat conversion layer, the photothermal conversion layer is completely or selectively converted into heat . In this design, the solar collector to become a part of the wall, it should be so that the solar collector device has a certain strength, and to satisfy the wall insulation and aesthetics[2].

\subsection{Combined with the Roof}

Building roof without cover and a wide range of contact with the sun, so it easy to the lighting and solar collector of solar hot water equipment. Solar collector roof close of flat roofs typically use overlay, with sloping roofs mosaic; same time to reduce the roof weight, solar collector alternative building insulation and insulation and can completely replace or partially replace the roof overburden, doing so can reduce costs and improve efficiency. In Kunming, Yunnan has built a flat roof structure of the solar building integrated heated swimming pool, the swimming pool roof area of about 700 square meters, the roof structure of light steel grid structure, roof covering completely special solar flat plate collector replace[3]. This experimental project is China's first on the flat roof building integrated solar energy.

\subsection{Combined with Balcony}

For high-rise building, the floor area can't meet the building all the installation of solar equipment, so people began to consider the use of the balcony, as well as the sunny side of the wall and other parts. But to do so would affect the aesthetics of the building facade and artistic effect. For this case, we can take household-type system, each household can solar collector device installed on the balcony the outer wall, the tube can be horizontally arranged in order to add the horizontal lines of the building, rich facade effect. Also in the south instead of railing use layout contiguous solar collector from bottom to top, as in the south facade, to provide centralized hot water supply in the whole building.

\subsection{Integration of Design Engineering Practice}

- “Quanjing Tian Yuan” district is located in Jinan City, local solar conditions quite three, annual sunshine hours between 2491-2737 hours (2007 data); annual average total solar radiation $5900-6200 \mathrm{MJ} / \mathrm{M}^{2} \cdot \mathrm{a}$, belong to more resource-rich region. The project covers an area of approximately $30 \mathrm{hm}^{2}$, total construction area of 600,000 $\mathrm{m}^{2}$, consisting of multi-storey residential, high-rise residential and public buildings. Residential district has been sold out a development of $160,000 \mathrm{~m}^{2}$ residential district two main types of building multi-story building, a plate of small high-rise buildings, point tower. Residential district developed a residential building have all been installed to force on Norit household wall- mounted solar hot water system and put into use, the residential buildings of the district two vacuum tube split solar installation force Norit's U-tube (in the same period) and hot water system is completed.

- Ecological planning and design of the new concept of high-grade energy-saving residential area, solar hot water system is an important part. Solar hot water systems of the program explicitly the balcony bar plate system (per set), the system of solar collectors using the U-pipe vacuum tube solar collector is used through walls fixed, combined with construction set15-year design life of the heater should meet (domestic like product are able to meet the times conditions), with of pipeline emptying and electric auxiliary heating system.

\subsection{Project Evaluation}

1) Analysis of the estimates, the solar hot water system, 
Table 2. Taking water heating systems using fuel economic comparison.

\begin{tabular}{lccc}
\hline \multicolumn{1}{c}{ sort } & Natural gas & electricity & Solar energy + electricity \\
\hline Heat value & $8470 \mathrm{Kcal} / \mathrm{m}^{2}$ & $860 \mathrm{Kcal} / \mathrm{KWh}$ & $4.5 \mathrm{KWh} / \mathrm{d}$ \\
Efficiency & $88 \%$ & $100 \%$ & $100 \%$ \\
Fuel expense & 1.04 & 2.15 & 0.43 \\
The percentage of running expense & $242 \%$ & $500 \%$ & $100 \%$ \\
Initial investment & 1000 & 2000 & 4000 \\
Service life & $5 \mathrm{a}$ & $15 \mathrm{a}$ & $15 \mathrm{a}$ \\
Equipment cost & 0.55 & 0.37 & 0.73 \\
Day running expense & 1.43 & 2.52 & 1.16 \\
Year expense & 522 & 920 & 423 \\
Total cost contrast & $123 \%$ & $217 \%$ & $100 \%$ \\
\hline
\end{tabular}

compared to other conventional energy systems, energy consumption and running costs of about $2 / 5$ of the gas water heater, electric water heater, 1/5. Comparison of the total cost of the solar hot water system program is also lower than gas hot water system or electric water heaters. The Jinan City local sunshine data analysis, annual sunshine hours of about 2491-2737 h, sunshine percentage in more than $60 \%$ of the hot water system can reduce the daily routine of life, energy consumption, more than $60 \%$ of the solar energy saving, we can see the economic benefits and energy-saving effect is very obvious(Table 2).

2) Per $100 \mathrm{~m}^{2}$ per year using solar hot water systems to reduce dust emissions $2.5 \mathrm{t}$ sulfur dioxide $0.25 \mathrm{t}$, carbon dioxide $0.9 \mathrm{t}$, good ecological benefits.

3) Install the collector to the balcony in the building south avoid rooftop checks, maintenance difficulties, the structural arrangement confusion and undermine the overall image of the building wall solar hot water system for the project selection; contrary to some extent on the building façade effect certain improvements, cash connotation of eco-built group to help improve people's quality of life, enhancing people's awareness of environmental protection and energy saving, and guide people in building a new type of savings and ecological communities.

\section{Concluding Remarks}

With the construction of ecological conservation and sustainable development of social thought deep human heart, solar hot water equipment in residential use and more widely, solar integrated design for the rational use of solar energy, solar energy utilization efficiency and improve the surrounding environment significance[4]. Al- though China has made some achievements in terms of solar hot water systems and building integrated research, but there are still many shortcomings, such as the best angle of sun and time by some of the hot water system collector, hot water inadequate security conditions senior collector tube drop. I believe in the government, society, and the majority of researchers in the continuous efforts of the solar and building integrated design will gradually improve, achieve energy saving and Eco win.

\section{REFERENCES}

[1] The Office of Standards for Engineering Design and Construction of Anhui Province, "Technical Standards for the Integration of the Use of Solar Energy and Architecture,” DB34854-2008.

[2] Y. H. Wang, "Design of Solar Residential Building Integration," Construction Conserves Energy, Vol. 38, No. 1, 2010, pp. 55-56.

[3] M. M. Liu and X. D. Jin, "Integrated Design of Building and Solar Energy Technology," Shanxi Architecture,Vol. 13, 2010, pp. 231-232.

[4] J. Tang, "On the Application Research on the Integral Solar-Energy System Based on the Architectural Integration,” Shanxi Architecture, 2008, Vol. 34, No. 35, pp. 254-255. 